\title{
Jovens irmãos de autistas: expectativas, sentimentos e convívio
}

\author{
Mayara Fernanda Cardoso ${ }^{1}$, Maria de Fátima de Campos Françozo ${ }^{2}$
}

\begin{abstract}
RESUMO
O autismo é um transtorno que apresenta grandes prejuízos desenvolvimentais, e, desta forma influencia de forma impactante a família. Poucos estudos abordam a influência na relação dos autistas com seus irmãos. Este estudo objetivou objetiva compreender a vivência de jovens irmãos de autistas. Tratou-se de uma pesquisa qualitativa, com o uso de entrevista semiestruturada. Os participantes foram cinco jovens irmãos de autistas. A técnica de análise temática foi usada para categorização e discussão. As categorias identificadas foram: conhecimento sobre o autismo; relacionamento, sentimentos e preocupações em relação ao irmão com autismo; mudanças na vida familiar. Os resultados revelaram explicação insuficiente para os irmãos sobre o autismo e mudanças significativas na vida familiar. Os participantes relataram deixar de realizar atividades sociais e vivenciar situações de preconceito, sendo uma preocupação, a necessidade de se responsabilizar pelo irmão no futuro. É fundamental o desenvolvimento de políticas voltadas para os irmãos de autistas.
\end{abstract}

Descritores: Transtorno Autístico; Irmãos; Relações Familiares.

\section{Autistic Siblings: expectations, feelings and acquaintanceship}

\begin{abstract}
Autism is a disorder that presents massive developmental prejudices, affecting drastically the family's environment. There are many studies about the influences of autism in the parents and autistic children relationship but there are not many references related to the siblings. This study aimed to comprehend the living experience of autistics siblings. A qualitative methodology was carried out using semi-structured interviews as a tool to collect data. The participants were five youngsters of autistics siblings. Content analysis was used to discuss the data. The knowledge about the autistic disorder; relationship, feelings and worries related to the sibling with autism; and the changes on family life were the main themes analyzed. The results showed that the participants were not aware of the autistic sibling's condition because there was not enough information for them. Significantly changes had occurred in the family's routine, the siblings were not able to do some activities due the autistic sibling condition. They suffer discrimination concerning the autistic sibling. Most participants worried about the responsibility for the autistic in the future. It is crucial to develop policies aiming to help the autistic siblings.
\end{abstract}

Descriptors: Autistic Disorder; Siblings; Family Relations.

\footnotetext{
${ }^{1}$ Fonoaudióloga pela Universidade Estadual de Campinas (UNICAMP), Campinas, SP, Brasil.

${ }^{2}$ Doutora em Saúde Mental pela Universidade Estadual de Campinas (UNICAMP), Campinas, SP, Brasil.
} 


\section{Introdução}

A relação familiar é a primeira na qual o indivíduo é inserido e fornece a base para sua organização biopsicossocial. É no contexto familiar que o indivíduo desenvolve sua personalidade e vivencia seus primeiros papéis em um grupo social. Portanto, a família é um suporte de extrema importância para o indivíduo no sentido de conduzi-lo a interação com a sociedade, desde a infância até à idade adulta ${ }^{1}$.

Inserida na vida familiar, a criança não desenvolverá uma relação apenas com a mãe, agregando também com outros agentes sociais, como pai, avós e irmãos ${ }^{2}$. A relação entre irmãos constitui, para a criança, uma transição entre o meio familiar e a sociedade propriamente dita, além disso, pode ser o mais duradouro de todos os relacionamentos familiares ${ }^{1}$. Assim, os irmãos podem manter relações de companheirismo, representando um laço familiar com grandes possibilidades de duração, compromisso e intensidade.

Sabe-se que irmãos e irmãs são pessoas concebidas ou reconhecidas pelo mesmo pai e/ou mãe ou as adotadas pelos mesmos pais. O convívio com o irmão é a primeira oportunidade que o indivíduo tem de negociar suas preferências e dividir a atenção dos pais. Autores explicam que nessa relação existem também os primeiros sentimentos de rivalidade, compromisso e competição ${ }^{1,2,3}$.

Apesar da clareza sobre a importância da relação de irmandade, a complexidade da família torna essa relação difícil de ser analisada. Tal dificuldade pode ficar ainda mais evidente quando existe a presença de um irmão com algum tipo de necessidade especial, como por exemplo, um irmão com autismo, uma vez que o autismo compromete principalmente a comunicação e vida social do indivíduo².

Atualmente a literatura apresenta como definição, transtorno do espectro autista, que se refere a uma classe de condições neurodesenvolvimentais que inclui o transtorno autístico, o de Asperger, o desintegrativo da infância e 0 transtorno global do desenvolvimento não especificado, também conhecido como autismo atípico 4 .

O Manual Diagnóstico e Estatístico de Transtornos Mentais ${ }^{5}$ define que os Transtornos Globais do Desenvolvimento (TGD) são comprometimentos graves e globais em algumas áreas do desenvolvimento e nesses transtornos está incluso o Transtorno Autista. As categorias comprometidas no autismo, de acordo com o DSM-5, são agrupadas em duas: déficits sociais e de comunicação e interesses fixados e comportamentos repetitivos.

Os autistas enfrentam dificuldades importantes na execução de tarefas cotidianas, uma vez que a as características do autismo envolvem dificuldades nas condições físicas e psicológicas do indivíduo, tornando maior a demanda por cuidado. Essas dificuldades podem ser minimizadas quando se tem empenho e o suporte familiar, sendo o vínculo, nesse caso, peça fundamental ${ }^{6}$.

Em levantamento bibliográfico ${ }^{1}$ sobre os autistas e seus irmãos a autora encontrou que parece existir consenso em relação à presença de problemas de comportamento nos irmãos de autistas, fato evidenciado pelos dados que apontam a existência de sentimentos negativos e noção de prejuízo interferindo negativamente na qualidade de vida desses irmãos. Além disso, a autora também afirma que os irmãos de autistas assumem mais responsabilidades de cuidados com o irmão, do que irmãos de crianças sem deficiência, o que pode gerar conflitos entre irmãos, diminuição de oportunidades de contato com outras crianças e diminuição de atividades de lazer.

De acordo com afirmações dos entrevistados em um estudo sobre pessoas com autismo e seus irmãos ${ }^{7}$, entre as causas de sentimentos negativos relacionados ao irmão com autismo estão a insegurança em relação ao futuro do irmão, o preconceito social, a ansiedade devido à incapacidade de diminuir o sofrimento; os problemas conjugais dos pais que se relacionam ao sentimento de culpa, dificuldade de aceitação, situação financeira; a frustração das expectativas quanto à independência do irmão, que podem levar ao desenvolvimento de estresse. Por outro lado, existem alguns estudos indicando que a convivência com irmãos autistas possuem mais referências positivas do que negativas ${ }^{3}$.

Levando em consideração que os sintomas de comportamentos-problemas são mais acentuados na adolescência e juventude do que em outras fases da vida, autores ${ }^{8}$ apontam a necessidade de considerar as dificuldades presentes nessa fase, pois irmãos de modo geral relatam ter um relacionamento mais conflituoso na adolescência se comparado à infância ou à idade adulta.

É possível afirmar, considerando-se os estudos apontados anteriormente, que irmãos podem sofrer influências pela presença de um irmão com autismo no cotidiano familiar, no entanto, embora existam muitos estudos que abordam a influência na relação dos filhos autistas com seus pais, essa mesma quantidade de literatura não é encontrada quando olhamos para as relações de autistas com seus irmãos ${ }^{1,3,8}$. No Brasil, poucos estudos contemplam essa temática.

0 objetivo do presente estudo foi compreender a vivência de jovens irmãos de autistas, buscando-se conhecer a percepção que irmãos têm em relação ao autismo, a rotina e o relacionamento entre os irmãos, assim como os sentimentos e as expectativas de irmãos em relação ao futuro do irmão autista. 


\section{Metodologia}

Tratou-se de uma pesquisa de caráter qualitativo, com a utilização de entrevistas para coletar dados. A abordagem qualitativa de pesquisa busca os significados que as pessoas atribuem às suas experiências ${ }^{9}$, favorecendo, portanto, 0 entendimento sobre as questões acerca do relacionamento entre irmãos.

$\mathrm{Na}$ coleta dos dados foram realizadas entrevistas semiestruturadas, guiadas por um roteiro de perguntas abertas e elaborado pelas pesquisadoras. As perguntas abordaram dados de como se deu a constatação do autismo, a presença do autista no âmbito familiar, como se dá o relacionamento entre irmãos, relacionamento com os pais, responsabilidade em relação ao irmão autista, autismo e a sociedade e planos e/ou preocupações em relação ao futuro de seu irmão. Ainda, para caracterizar o grupo familiar, foram coletados dados relativos às condições socioeconômicas e a constituição atual das famílias.

Durante uma entrevista, previamente agendada, os participantes expressaram opiniões e sentimentos em relação ao irmão autista. A entrevista foi realizada uma única vez e em locais de consenso entre entrevistadora e entrevistado. Os locais escolhidos foram públicos, mas adequados aos propósitos de segurança e privacidade.

Foi necessária a utilização de um gravador, por meio de uma prévia aquiescência dos entrevistados, com a finalidade de manter a fidedignidade de tudo que foi dito. Cada entrevista durou em média 40 minutos, depois, foram ouvidas, lidas e transcritas pela própria pesquisadora. Os nomes dos entrevistados foram excluídos e cada entrevista recebeu um número, para manter o anonimato dos participantes. Neste texto, cada participante recebeu uma letra do alfabeto que não a do próprio nome.

Os participantes desse estudo foram 05 adolescentes ou jovens que tem um irmão com autismo. Foram contatados através de profissionais de fonoaudiologia que indicaram irmãos de crianças ou adolescentes autistas em atendimento ou que já haviam sido atendidos, e também em busca direta da pesquisadora com pessoas do convívio diário. A amostra foi intencional, ou seja, a escolha dos participantes se faz intencionalmente em função das características que apresentam em relação ao assunto de investigação $0^{10}$. 0 número de participantes foi definido com 0 decorrer da coleta de dados, sendo interrompida ao se identificar a repetição de informação. A coleta de dados foi realizada na região de Campinas, estado de São Paulo, no segundo semestre de 2012.

Foram considerados como critérios de inclusão: o participante ter um irmão com diagnóstico de autismo sem ter outras deficiências associadas, ter acima de 14 anos de idade, residir ou ter residido por, no mínimo, cinco anos com o irmão autista e assinar o Termo de Consentimento Livre e Esclarecido (TCLE).

Alguns mecanismos foram observados para se evitar a indução das respostas dadas pelos participantes. 0 primeiro deles foi elaboração criteriosa de cada pergunta do roteiro. Além disso, também foi efetuado o teste do roteiro da entrevista para verificar a adequação das questões antes da coleta de dados.

Após a transcrição e várias leituras do conteúdo das entrevistas, foram identificados índices, frases e conteúdos que traziam significado considerando os objetivos deste estudo. A seguir, foram elencadas categorias de análise e o agrupamento dos conteúdos, buscando-se os núcleos de sentido ${ }^{11}$. Como último passo foi efetuada a descrição e análise dos dados.

Apesar da dificuldade em encontrar irmãos de autistas que se colocassem a disposição para participar da pesquisa, nenhum participante desistiu no meio da entrevista .

A pesquisa foi encaminhada ao Comitê de Ética em Pesquisa da Faculdade de Ciência Médicas da Universidade Estadual de Campinas e aprovada em 12/12/ 2012, sob Parecer n 121.261.

Todos participantes e/ou seus responsáveis assinaram o termo de consenti-mento livre e esclarecido (TCLE). Um único participante tinha menos de 18 anos de idade e para garantir que ele ficasse à vontade para responder às questões a entrevista foi realizada em um espaço em que a responsável não tinha acesso ao conteúdo da conversa, assim, foi possível evitar que as opiniões dela influenciassem a resposta do adolescente.

\section{Resultados e discussão}

\section{Caracterização dos participantes}

Os participantes foram cinco irmãos na faixa etária entre 14 e 31 anos (média de 22 anos), 4 do sexo masculino e 1 do sexo feminino. Quatro deles primogênitos, sendo um gêmeo do jovem com autismo e um participante era o segundo filho. A renda familiar variou de 2 a mais de 10 salários mínimos (média 6) e o número de pessoas residentes na casa variou de 1 a 4 (media 2,8). 
Considerando-se a composição familiar pode-se depreender que as famílias, em geral, têm um número pequeno de pessoas e uma renda per capita média de aproximadamente 2 salários mínimos. Além disso, no estudo há uma predominância de participantes do sexo masculino se comparado ao feminino.

\section{1 - Conhecimento do irmão sobre o autismo}

Os irmãos também sofrem pelo impacto do nascimento do autista, uma vez que necessitam lidar com a frustração do sonho do irmão perfeito, assim como os pais ${ }^{3}$. O diagnóstico do autismo pode ser compreendido de forma diversa entre os diferentes membros da família, dependendo de inúmeros fatores, dentre eles, a forma como foram esclarecidos sobre o diagnóstico.

Os resultados de nosso estudo revelaram que houve explicação insuficiente para o irmão sobre o autismo, o que pode ser exemplificado pela fala abaixo:

"Eu acho que ninguém nunca me contou, eu fiquei sabendo aos poucos." (P1)

Em alguns casos não se falou sobre o autismo com o irmão, no entanto, alguns deles foram percebendo algo diferente no comportamento do irmão com autismo:

"Ele não brincava e eu comecei a perceber." (P2)

"Então, a gente percebia que ele tinha um jeito diferente né. Foi uma coisa que a gente foi percebendo, assim..." (P3)

Em contrapartida, um estudo realizado na cidade de Viseu em Portugal apresentou resultado divergente do presente estudo, revelando grande abertura dos pais para informar aos filhos sobre aquilo que sabiam sobre 0 autismo, transmitindo-a aos irmãos para que estes se adaptassem da melhor forma à criança ${ }^{3}$.

Para outros participantes, o fato de ser mais novo implicou maior demora no entendimento da situação do irmão:

"Então assim, eu não me lembro de quando eu descobri que o P. era uma pessoa especial, mas porque eu já convivi com ele nessa situação." (P4)

"Acho que mesmo por eu ser bem novinho quando a gente ficou sabendo, eles meio que não me explicaram assim. Tanto que quando falaram pra mim pela primeira vez 'sua irmã é autista' eu não fazia ideia do que era. Eu fui descobrindo as características mesmo com o passar do tempo". (P5)

Em um caso o não entendimento resultou em sentimento de tristeza pelo irmão. Ou seja, ainda que muito jovem, o participante percebia de alguma forma, as dificuldades do irmão:

"Eu fiquei triste né, porque eu não entendia direito o que era assim, não sabia o que ia ser dele. Mas aí com o tempo ficou tranquilo." (P3)

Outros tomaram consciência da situação do irmão no contexto da instituição de atendimento:

"Quando eu tinha uns doze anos eu ia muito com a minha mãe para a escola de G., eu estudava e na parte da tarde como eu não tinha com quem ficar eu ia com ela. Então lá eu até conversava, ouvia, mais ouvia do que falava né, então foi lá que eu comecei a entender um pouco melhor. Foi lá que eu vi assim crianças com outros graus de autismo, como elas se comportavam e tudo mais." (P5)

Os dados anteriormente indicam diferenças nos sentimentos dos irmãos no momento do diagnóstico. Em um estudo semelhante, autores encontraram que a percepção das diferenças na atenção dispensada pelos pais aos filhos pode ter preparado esses irmãos para o diagnóstico. No entanto, mesmo já vivenciando a condição do irmão por um período de tempo, alguns participantes mencionaram sofrimento e preocupação ao se defrontarem com o diagnóstico propriamente e com a realidade das características do autismo? 
Uma das preocupações enfrentadas por irmãos e irmãs de indivíduos com algum tipo de necessidade especial refere-se às dúvidas sobre o que causou a deficiência e sobre os motivos que levam o irmão a se comportar de maneira diferente ${ }^{12}$.

Um ponto importante de um dos relatos descritos anteriormente se refere à necessidade de que a intervenção terapêutica não inclua somente o autista e os pais, mas também os irmãos, uma vez que constituem os primeiros agentes de socialização, sendo uma importante fonte de suporte informal. 0 irmão deve, portanto, ser envolvido no atendimento com o autista e quanto mais rápida for a intervenção no subsistema fraternal, maior será o envolvimento entre irmãos ao longo da vida ${ }^{3}$.

\section{$\underline{2 \text { - Mudanças na vida familiar }}$}

Os participantes relataram mudanças significativas na vida familiar em razão da diferença no comportamento do irmão. Um deles relatou a necessidade de mudança de cidade, o que, por si só, pode implicar muitas vezes em mudanças de relacionamentos, de amigos e de escola para outros membros da família também:

"Algumas coisas mudaram bastante, porque a gente mudou de cidade pra buscar uma escola que atendesse melhor às necessidades dele." (P3)

Mudanças na vida social da família também foram relatadas:

"Por ela ser autista nós não recebemos muitas pessoas em casa (...) Eu, meu pai, minha mãe e ela, nós somos bem unidos, mas assim com o resto da família até que a gente faz visitas e tudo mais, mas não tem um contato tão próximo das pessoas virem até a gente." (P5)

"Só de vem em quando [as pessoas frequentam a casa], quase nunca por causa que de vez ele está estressado e não gosta."

Podemos considerar que nesses casos, há certo isolamento da família em relação à vida social, evitando a exposição do autista a certos ambientes e situações.

Outros estudos ${ }^{13,14}$ também encontraram o isolamento social como importante mudança na vida familiar em razão da dificuldade de lidar com os comportamentos do filho com autismo. Para um desses autores ${ }^{13}$, ficar em casa significa poupar os filhos dos olhares discriminatórios por parte de outras pessoas, que, muitas vezes, tem pouco conhecimento, pouco entendimento sobre o autismo. Nesse sentido, é esclarecedora a fala de um dos participantes de nosso estudo:

"O que mudou também é que a gente sempre tem que dar uma explicação quando conhece alguém novo." (P5)

Mudanças na relação com o irmão foram relatadas por alguns participantes:

"Que eu tive mais paciência com ele, por que antes de saber eu não tinha muita paciência com ele. Ai quando eu soube, eu fiquei mais paciente." (P2)

Um participante menciona seu papel de incluir o irmão em atividades sociais e ao fazer isso, lida com uma dificuldade da mãe de também realizar essa inclusão:

\footnotetext{
"Minha mãe não viajava, minha mãe tinha um monte de trauma por conta do P. e por conta de tudo que ele foi. E eu acho que foi muito movimento meu de fazer essa inclusão social do $P$. no sentido de levar ele em restaurante (...) minha mãe não tinha coragem de fazer isso, não tinha coragem." (P4)
}

É comum que o irmão sem deficiência procure compensar a sobrecarga de cuidado da mãe exercendo o cuidado direto ao irmão com autismo, buscando cuidar, brincar, ajudar na limpeza higiênica ou também através de ajuda indireta, como por exemplo, nos afazeres da casa ${ }^{15}$. Assim, muitas vezes esses irmãos já iniciam sua responsabilização por alguns cuidados com o irmão autista antes mesmo que exista essa necessidade. 


\section{$\underline{3-\text { Cotidiano }}$}

No cotidiano, as famílias deixam de realizar algumas atividades de lazer em função do comportamento do filho decorrente das características do autismo. A participação em atividades sociais exige atenção especial às características do ambiente, como por exemplo: quantidade de pessoas que estarão no local, nível de ruído, dentre outras. Por isso, as atividades precisam ser planejadas e ainda assim, algumas vezes, essas atividades precisam ser interrompidas em função do irmão autista, como relatado nos exemplos a seguir:

"De vez em quando, só quando nós vai em festa ele fica estressado e nós tem que voltar pra casa." (P2)

"Lugares muito lotados, lugares que não vai dar pra ela ter um cuidado ou então que a gente sabe que vai causar algum constrangimento maior." (P5)

Outras vezes, o participante afirma que prefere realizar atividades com a irmã na presença dos pais:

"Eu não costumo sair com ela para outros lugares, passear só eu e ela. Eu sempre gosto de ir, mas eu, ela e minha mãe ou eu, ela e meu pai (...) mais uma pessoa pra ficar olhando." (P5)

Em algumas situações há impossibilidade de realizar a atividade social, pela atenção que o irmão com autismo exige:

"Eu gosto de levar ele pra casa dos outros pra brincar e não gosto de levar ele quando é trabalho e essas coisas, não gosto. Por que eu tenho que ficar olhando pra ele e não trabalho." (P2)

Um dos motivos de dificuldade para a inserção do irmão em ambientes sociais envolve os comportamentos apresentados por autistas, tais como agitação, gritos o agressividade ${ }^{8}$.

"Eu levei ele, ele foi, mas na hora de ir embora ele me agrediu. Então foi uma situação complicada, mas assim não que isso impossibilitou, mas a gente tem que tomar todos os cuidados pra levar o P. pra fazer as coisas." (P4)

O irmão de um autista enfrenta "frequentemente a ausência dos pais, devido à grande atenção voltada ao irmão, que necessita de atenção em tempo integral e idas aos profissionais de saúde rotineiramente" (p.553-561)8. As falas dos participantes indicam diferenças no tratamento dispensado pelos pais aos filhos, quando comparado ao irmão autista:

"De vez em quando ela trata os dois iguais." (P1)

"Mais atenção não, acredito que de atenção sempre foi igual. É claro uma coisa assim de proteção mesmo foi diferente entendeu? Tanto que eles [os pais] falavam pra mim de como ela é, que eles precisavam da minha ajuda." (P5)

Outros participantes do presente estudo expressaram opiniões diferentes quanto a essa atenção dispensada pelos pais aos filhos. No depoimento a seguir, apesar de o participante não se queixar da ausência dos pais, afirma que toda a atenção se voltou para o irmão autista, incluindo a atenção do próprio participante.

"De repente quando ele [o irmão com autismo] surgiu assim, a atenção foi toda pra ele, inclusive eu dediquei atenção pra ele." (P3)

Conviver com o autismo é, para a família, uma tarefa árdua, difícil, cansativa e, por vezes, dolorosa e, considerando a importância de atividades de lazer, o isolamento social pode tornar essa convivência ainda mais difícili13. 


\section{4 - Relacionamento e sentimentos em relação ao irmão}

Todos os participantes descreveram a relação com o irmão com autismo como muito boa, mesmo com as limitações de interação, característica do autismo. Outro estudo também evidencia que os irmãos nutrem sentimentos favoráveis em relação ao irmão autista ${ }^{3}$.

"Eu estou vendo ela pouco, mas eu gosto muito dela. Por sempre ter que cuidar e tudo mais. Tem irmãos que os dois são saudáveis e não tem uma relação tão forte. Eu tento ficar com ela o máximo possível, conversar, fazer com que ela fale. Ela comigo também sabe, me vê, me procura, sabe?" (P5)

"O P. pra mim nunca foi um problema, eu sempre fui muito apaixonada pelo meu irmão. Ele sempre foi um menino muito feliz." (P4)

Em um caso específico em que o irmão é gêmeo, a relação entre eles foi verbalizada como de muita proximidade, como de grande apego:

"Não, eu tenho mais segredos com ele. Eu conto tudo pra ele, eu faço tudo com ele (...) eu durmo, eu tomo banho." (P2)

No entanto, ao pensar na relação, um dos irmãos afirma que poderia ser melhor:

"Poderia ser melhor, eu poderia sair mais com ele, mas acabo não saindo. Acabo saindo mais com meus amigos e tal. Mas não é ruim não (...) ele gosta de mim e que ele preocupa comigo sim. Ele também tem consciência de que eu vou cuidar dele, ele fala pra mim: quando o pai e a mãe morrer você que vai cuidar de mim né." (P1)

Outros enfatizaram que o maior sentimento em relação ao irmão é de cuidado e proteção:

"Eu sempre tive um sentimento muito fraternal, muito de querer cuidar do P.. Sempre me lembro de muito nova cuidando dele. De limpar ele, de ajudar ele comer, de estar preocupada com o que ele estava fazendo ou não (...) Então assim, se você falar qual é o sentimento que você teve com o P., é preocupação." (P4)

Algumas dificuldades também foram relatadas no relacionamento com o irmão autista:

"A mais clara que é a verbal né, de comunicação, mas também porque uma das características do autismo é que, às vezes, ela está quietinha e, às vezes, super agitada né. Então é difícil lidar com isso, mesmo com muito tempo assim essa coisa de você saber como agir no momento que ela está é difícil." (P5)

Nos relatos os participantes declararam que a adolescência foi o período mais crítico para a convivência com o irmão autista.

"Pro irmão eu acho que é isso, a época mais difícil dessa situação [adolescência] depois a gente vai aprendendo a lidar com essas situações." (P3)

A presença de uma criança com autismo no âmbito familiar é um fator desestruturante em menor ou maior grau, para os membros envolvidos nessa relação. Alguns estudos apontam resultados divergentes em relação ao impacto da pessoa com autismo na vida do irmão, entretanto, a literatura está de acordo quanto ao fato de que o impacto de se ter um irmão com autismo de alguma forma influenciará no comportamento do irmão sem deficiência ${ }^{15}$.

\section{$\underline{5-O \text { autista na sociedade }}$}

Os irmãos relataram dificuldades na inserção do autista na sociedade e no círculo de amizades.

"Tem pessoas que talvez por uma coisa de contar uma piada e algo assim acaba brincando com essa questão da pessoa deficiente, dai esse tipo de pessoa eu não gosto tanto de falar" [sobre o autismo]. (P5) 
"Eu nunca tive vergonha, nunca, nunca. De verdade assim se você falar, às vezes assim eu fico muito constrangida por ele, por algumas situações que a gente passa, entendeu? Eu fico muito revoltada com a reação das pessoas, mas pra mim nunca." (P4)

Autores afirmam que os irmãos, por diversas vezes, podem exercer o papel de agentes de socialização entre as pessoas e 0 autista ${ }^{16}$. Tais achados corroboram com os resultados do presente estudo, em que os participantes relataram que promovem essa inclusão do autista em ambiente social, mesmo que, às vezes, necessitem da presença dos pais para fazê-lo. Exemplo dessa socialização foi descrito pelo participante abaixo:

"Eu sempre fui a pessoa assim, sempre levei ele pra passear, andar de avião, todos os restaurantes de Campinas eu levei ele. Todo tipo de festa, mas a minha mãe tinha muito mais preocupação, eu consegui voltar a colocar o P. e hoje isso vira uma coisa natural. As pessoas veem que a gente faz e, as vezes, até faz com ele". (P4)

Foram significativas as falas dos irmãos ao relatarem sobre o momento em que contam aos amigos e conhecidos sobre 0 autismo do irmão.

\begin{abstract}
"Quem eu conheço assim eu falo normal, mas quem eu não conheço fico receoso de falar. Mas também não demora muito pra saber. Por exemplo, conheci uma menina, eu não vou falar do meu irmão direto." (P1)

"Eu conto, às vezes mais cedo, às vezes mais tarde, mas conto [sobre o irmão autista]. É claro que quando eu vou contar pra eles eu falo: olha, 'você vai conhecer minha irmã e tal', não é uma situação normal. Não adianta falar 'pode ficar tranquilo, você vai saber como agir'. Talvez a pessoa fica encabulada. Algumas pessoas ficam até meio constrangidas mas não por ela ser autista em si, mas por ser meu amigo e não saber como lidar com a minha irmã entendeu?" (P5)
\end{abstract}

Em estudo sobre o impacto da deficiência nos irmãos ouviram relatos de constrangimento em algum período da vida em relação à deficiência, principalmente quando questionados por pessoas ou no contato social ${ }^{17}$. Tal fato pode se relacionar com as afirmações acima, em que os participantes se sentem incomodados em algumas situações de falar sobre o autismo do irmão. Em outro estudo autores encontraram relatos de que ter um irmão especial é um diferencial, de modo que não consideram isso como um ponto negativo, do qual se envergonhem. Aliás, os irmãos ressaltam que fazem questão de dizer que têm um irmão especial, até mesmo para diminuir o preconceito e a falta de informação existente ${ }^{17}$.

Todos os participantes mencionaram a vivencia de situações de preconceito em relação ao irmão com autismo, seja no olhar, seja nas atitudes de outras pessoas:

"E, às vezes, também a gente indo pra certos lugares do jeito que ela fica, talvez não cause nenhum problema, mas só das pessoas ao redor ficarem olhando e, às vezes, fazendo, julgando, assim e tudo mais, a gente tenta se preservar." (P5)

Ainda criança o preconceito foi percebido por um dos participantes:

"Quando eu tinha uns 8 anos o povo só queria brincar comigo e não queria brincar com ele. Aí eu fiquei conversando com os outros e aí mudou." (P2)

Para outro participante a identificação de situações de preconceito não aconteceu na infância, mas sim posteriormente:

"Inclusive eu não sentia muito quando era criança né, mas depois". (P3)

Houve menção de situações mais constrangedoras como no impedimento do contato, revelado no trecho a seguir:

"Eu já vi mães de crianças pequenas falando para o filho assim: 'não fica muito perto dela', por que pensa que a criança vai assimilar os jeitos. A pessoa sabe que o autismo não é contagioso, mas o jeito dela fazer com a mão, de falar assim (...) ela não queria que a criança absorvesse isso". (P5) 
A desinformação das pessoas a respeito do autismo ainda é grande, o que pode fomentar o preconceito e dificultar a inclusão. No Brasil construiu-se uma imagem exacerbada sobre os comportamentos das crianças com autismo e, desta maneira, crê-se que são agressivas, sem condições de aprender, submersas em seu mundo particular e até mesmo uma ameaça para outras crianças e que por isso devem frequentar ambientes terapêuticos segregados ${ }^{18}$.

\section{6 - Preocupação em relação ao futuro do irmão com autismo e influência nas decisões pessoais}

A maior preocupação dos irmãos diz respeito à necessidade de se responsabilizar pelos cuidados do autista no futuro. Todos os entrevistados apontaram essa preocupação antes mesmo de serem questionados pela entrevistadora quanto a isso, o que evidencia sua importância. No entanto, é diversificada a forma de lidar com essa situação. Na fala a seguir, o participante já assume que será responsável futuramente pelo irmão autista, além disso, tem atitudes que se relacionam a isso:

"Achei o seguinte: eu vou ter sempre uma obrigação a mais, querendo ou não ele vai morar comigo quando meus pais falecerem, né. Ele vai ser sempre parte da minha vida, estou consciente (...) Então, quando eu tinha uns 17, 18 anos fiquei meio assim né, não vou falar que eu gostei, eu não gostei.

Outro participante afirma que assimilou a ideia desses cuidados aos poucos:

"Ninguém gosta. Normal, mas fui aprendendo com as dificuldades e tudo mais, a lidar. Acostumei com a ideia, coloquei na cabeça, amadurece." (P1)

Um irmão afirma ter a expectativa de realizar esse cuidado, no entanto, parece ainda não realiza-lo:

"Eu acho que ele vai depender de mim né." (P2)

Outro ainda demonstra que já incorporou parte do cuidado:

"O sentimento que eu acho que aumentou foi uma coisa de proteção assim, meus pais sempre contaram muito comigo pra cuidar dela. Eu fui mais zeloso do que se ela não tivesse nada". (P5)

As preocupações veem permeadas por sentimentos e, embora nem sempre seja fácil falar de sentimentos, alguns se emocionaram com o conteúdo das respostas, o que expressa a carga psicológica que permeia essa relação, como na declaração abaixo:

"Quando eu estou com dor assim ele vai lá no meu lado. Ficar do meu lado. Até me emocionei [ao falar disso na entrevista]." (P2)

Ainda a respeito dessas diferenças, podemos observar relatos de participantes que já estão se preparando para assumir esses cuidados:

"Eu sempre fiz planos para que essa assistência possa ser dada da melhor maneira possivel". (P5)

Outro irmão afirma já realizar esse cuidado e que a ausência dos pais só irá acentuar esse cuidado dispensado:

"Pra mim, na falta dos meus pais a G. vai estar comigo e como já estou acostumado e tenho cuidado dela desde pequena, isso vai só aumentar o que eu já vivo, entendeu? É claro que eu vou sentir a falta deles que cuidam mais dela, não vou saber agir em determinadas situações, mas já tenho uma base, já sei como é”. (P5)

Como menciona um dos participantes, parece não ter havido a possibilidade de escolha para ela, no sentido de cuidar ou não do irmão: 
"Mas minha mãe sempre deixou isso muito claro: que um dia o P. ia ficar comigo. Sempre deixou isso muito claro, sempre me preparava 'olha filha o $P$. pra dormir tem que fazer assim, olha filha o P. assim', ela sempre me deixava a par do que estava acontecendo na vida do P. pra que eu realmente soubesse o que esta acontecendo na vida do P.(...) Eu sou a cuidadora do meu irmão, sempre fui assim, te falei ne? Desde criança eu aprendi a dar banho no P., aprendi a cuidar do cabelo dele, cortar a unha dele, colocar roupa nele. Então assim é uma coisa que você fala: desde quando? Não sei, mas desde muito cedo. Eu sempre fui uma certa cuidadora". (P4)

Com base na ideia de que os irmãos influenciam o comportamento uns dos outros, pesquisadores ${ }^{2}$ investigaram a relação entre gênero dos irmãos e o aprendizado de tarefas. Descobriram que as meninas são mais eficientes do que os meninos para ensinar uma tarefa aos irmãos e irmãs mais novos. Os meninos, ao contrário, tendem a ser mais eficientes para ensinar outras crianças mais jovens, não parentes, do que seus próprios irmãos e irmãs. Sendo assim, os dados acima nos levam a questionar o cuidado dispensado pelos irmãos aos autistas levando em consideração o gênero do irmão.

Pesquisando sobre a influência do gênero nos cuidados dispensados ao irmão autista, uma pesquisa ${ }^{1}$ afirma que as mulheres expressam mais implicações de ter um irmão autista na vida pessoal que os rapazes. Essas implicações envolvem: ter de acompanhar o irmão com autismo frequentemente, ter de o ajudar em tudo, ter de o compreender sempre, sentir pouca atenção por parte dos pais, observar que as prioridades dos pais são todas para o irmão autista e por fim não sair de casa pela possibilidade de passar vergonha com as atitudes comportamentais do irmão autista.

Alguns irmãos relataram influencias de ter um irmão com autismo em suas decisões pessoais, uma vez que, a relação entre os irmãos compõe, juntamente com os pais, significativos modelos de comportamento que preparam os indivíduos para as relações sociais com o grupo mais amplo ${ }^{7}$. A partir dessas relações são construídos, pela convivência e compartilhamento de experiências, os papéis sociais, valores, normas de conduta e comportamentos. Assim, a percepção dos cuidados permanentes e ininterruptos dispensados ao irmão com autismo parece gerar maior senso de responsabilidade nos irmãos, o que pode ser exemplificado pelas falas abaixo:

"Interfere, porque eu tenho que ter mais responsabilidade entendeu? Eu tenho que ter consciência que ela vai depender de mim e dos meus pais. Então eu sempre penso, pelo menos assim tento pensar nela também. "(P5)

"Então, eu tive que amadurecer um pouco antes. Eu tive que escolher uma carreira, fazer assim alguma coisa que me desse retorno porque eu sabia que lá na frente eu teria já um filho grande né." (P1)

Os pais de crianças com autismo têm tendência a responsabilizar o filho sem autismo para que este seja capaz de cuidar do irmão, no entanto, é possível identificar diferenças nesses cuidados entre os participantes do presente estudo e contradição ao comparar os achados com outra pesquisa que abordou a mesma temática. Nessa outra pesquisa, os irmãos demonstram incerteza quanto ao fato de assumirem demasiadas responsabilidades em relação ao cuidado do irmão com autismo ${ }^{3}$.

Ter um membro na família com autismo gera transformações em relação às expectativas com o futuro daquele indivíduo e com seu processo de crescimento ${ }^{19}$.

Ainda que cada integrante do sistema familiar vivencie a presença do autista de uma forma diferente, todos serão influenciados: os pais se tornam pais do autista, os irmãos do autista e com isso, todos em seus espaços singulares necessitam reorganizar-se a partir desta configuração ${ }^{19}$. Particularmente na analise das relações entre os irmãos de pessoas com autismo existem muitas divergências, condicionadas aos fatores sociais, psicológicos, pessoais, familiares, culturais, econômicos e etc., no entanto, a preocupação em relação ao futuro do irmão com autismo parece ser frequente nessa população.

\section{Considerações Finais}

As vivências de irmãos de jovens com autismo implica olhar para diversos e múltiplos aspectos. Nosso estudo focou nos relacionamentos, nos sentimentos e nas mudanças que ocorreram após o diagnóstico do autismo em um irmão. 
Na maioria dos casos investigados o diagnóstico do autismo não foi explicado aos irmãos ou a explicação foi insuficiente. Os participantes foram, ao longo do tempo, compreendendo o comportamento diferente do irmão. Os relatos indicam a necessidade de que os irmãos recebam informações sobre as características do autismo a fim de que lidem melhor com a situação.

As dificuldades de socialização do irmão com autismo levou algumas famílias a maior permanência ao ambiente doméstico, evitando ambientes sociais e modificando rotinas. 0 enfrentamento de preconceito em relação ao irmão também fez parte das vivências dos participantes.

0 cuidado e 0 afeto em relação a seus irmãos com autismo foram relatados pelos participantes e a mais evidente preocupação destes irmãos está em relação aos cuidados que deverão prestar ao irmão com autismo no futuro, sendo que alguns já realizam ações nesse sentido.

Vale afirmar, em função dos resultados encontrados, a necessidade de implementar intervenções destinadas aos irmãos de autistas em um espaço em que as dúvidas possam ser esclarecidas sobre as características do autismo, bem como receber orientação familiar. A possibilidade de compartilhar experiências entre irmãos pode ser desenvolvida por instituições que atendem pessoas com autismo.

Nossos achados corroboram com o estudo ${ }^{1}$ que evidencia a necessidade de que os profissionais de saúde estejam atentos às dificuldades dos irmãos ao longo de todo o processo terapêutico dos autistas.

Há necessidade de políticas de apoio às famílias com pessoas com autismo que possam favorecer também as vivências dos irmãos.

\section{Agradecimentos}

Agradecemos ao subsídio financeiro realizado pelo PIBIC/CNPQ.

\section{Referências Bibliográficas}

1. Pais IDB. Qualidade de Vida dos Irmãos de Indivíduos com Autismo [dissertação]. Viseu/Portugal, Escola Superior de Educação de Viseu, 2012.

2. Nunes CC, Aiello ALR. Interação entre Irmãos: Deficiência Mental, Idade e Apoio Social da Família. Psicologia: Reflexão e Crítica, 2007; 21(1):42-50.

3. Santos IAV. As necessidades dos irmãos de crianças e jovens com perturbações do espectro do autismo [dissertação]. Viseu/Portugal, Escola Superior de Educação de Viseu, 2014.

4. Zanon RB. Déficit na iniciativa de atenção compartilhada como principal preditor de comportamento social no transtorno do espectro autista. Dissertação de mestrado. Porto Alegre. UFRGS, 2012.

5. American Psichiatric Association, DSM-5 Manual Diagnóstico e Estatístico de Transtornos Mentais, Porto Alegre: Artmed, 2014. 6. Schmidt C; Dell'aglio D, Bosa C. Estratégias de coping de mães de portadores de autismo: lidando com dificuldades e com a emoção. Psicologia: Reflexão e Crítica, 2007; 124-31.

7. Pietszak, OS, Facion RJ. Pessoas com autismo e seus irmãos. Inter Saberes: Revista científica, 2006; 1(1):168-85.

8. Gomes FV, Bosa C. Estresse e relações familiares na perspectiva de irmãos de indivíduos com Transtornos Globais do Desenvolvimento. Estudos de Psicologia, 2004; 9(3):553-61.

9. Pope C, Mays N. (organizadores). Pesquisa qualitativa na atenção à saúde. $3^{a}$ ed. Porto Alegre: Artmed; 2009.

10. Turato, ER. Tratado da metodologia de pesquisa clínico-qualitativa: Construção teórico-epistemológica, discussão comparada e aplicação nas áreas da saúde e humanas. Petrópolis: Vozes, 2003.

11. Bardin L. Análise de Conteúdo. (edição revista e atualizada) Edições 70, Lisboa/Portugal, março de 2010.

12. Gargiulo RM. Special Education in Contemporary Society: An Introduction to Expeptionality. EUA:Thomson Learning, 2003; 513 - 540.

13. Zanatta EA. Menegazzo E, Guimarães NA, Ferraz L, Motta MGC. Cotidiano de famílias que convivem com o autismo infantil. Revista Baiana de Enfermagem, 2014; 28(3):271-282.

14. Segeren L, Françozo MFC. As vivências de mães de jovens autistas. Psicologia em Estudo, 201419 (1), 39-46.

15. Araujo RR, Silva JRS. D'antino MEF. Breve discussão sobre o impacto de se ter um irmão com Transtorno do Espectro do Autismo. Cadernos de Pós-Graduação em Distúrbios do Desenvolvimento, 2012; 12(1):9-15. 
16. Fernandes AMGM. O Estudo de uma Família com uma Criança Autista. 141 f. Dissertação (Ciências da Computação). Vila Real, Portugal, Universidade de Trás-os-Montes e Alto Douro, 2010.

17. MessaAA, Fiamenghi JRGA. O impacto da deficiência nos imãos: histórias de vida. Ciência \& Saúde Coletiva, 2010; 15(2):529-38. 18. Orrú ES. O perigo da supervalorização do diagnóstico: rótulos introdutórios ao fracasso escolar de crianças com autismo. Revista Eletrônica Gestão \& Saúde, 2013; 04(01):1699-709.

19. Souza PPM, Alves PP. Dialogando sobre o autismo e seus reflexos na família : contribuições da perspectiva dialógica. Revista de Psicologia da Criança e do Adolescente. 2014; 5 (1): 223-230.

\section{Mayara Fernanda Cardoso}

Endereço para correspondência - Rua Votorantim, nº 100, Ap 96, Vila Nova, CEP: 13073-090, Campinas, SP, Brasil.

E-mail: mayaracardosofono@gmail.com

Lattes: http://lattes.cnpq.br/4285414424399119

Maria de Fátima de Campos Françozo - mfcf@fcm.unicamp.br

\section{Enviado em 30 de agosto de 2014. Aceito em 18 de julho de 2015.}

